Original article

\title{
EVALUATION OF PLASMA TRACE ELEMENTS AND OXIDANT/ANTIOXIDANT STATUS IN BOERBOEL DOGS WITH HIP DYSPLASIA
}

\author{
R. A. AJADI, J. L. SANNI, E. F. SOBAYO \& O. K. IJAOPO \\ Department of Veterinary Medicine and Surgery, Federal University of Agriculture, \\ Abeokuta, Nigeria
}

\section{Summary}

Ajadi, R. A., J. L. Sanni, E. F. Sobayo \& O. K. Ijaopo, 2020. Evaluation of plasma trace elements and oxidant/antioxidant status in Boerboel dogs with hip dysplasia. Bulg. J. Vet. Med., 23, No 2, 237-247.

Changes in plasma concentrations of trace elements and oxidants/antioxidants were evaluated in twenty healthy Boerboels of both sexes and median age of 2 years. Antero-posterior and flexed lateral radiographs of the hip were obtained using digital x-ray machine and hip grading was done according to Fédération Cynologique Internationale (FCI) system. Blood was collected from the cephalic vein for determination of plasma concentrations of manganese $(\mathrm{Mn})$, magnesium $(\mathrm{Mg})$, copper $(\mathrm{Cu})$, cobalt (Co), malondialdehyde (MDA), superoxide dismutase (SOD), glutathione (GSH), glutathione peroxidase (GPX) and Vitamin E. Correlation between the parameters was done using Pearson's correlation. Eleven (11/20) of the Boerboel dogs had hip dysplasia (HD), comprising five (5/9) males and six (6/11) females. Plasma $\mathrm{Mn}, \mathrm{Cu}$ and $\mathrm{Co}$ were insignificantly higher in Boerboels with normal hips than those with HD. MDA concentration was significantly $(\mathrm{P}<0.05)$ lower in Boerboels with normal hips $(0.75 \pm 0.84 \mu \mathrm{mol} / \mathrm{L})$ than in dogs with $\mathrm{HD}(1.77 \pm 0.78 \mu \mathrm{mol} / \mathrm{L})$, while SOD was significantly $(\mathrm{P}<0.05)$ higher in Boerboels with normal hips $(0.65 \pm 0.22 \mathrm{U} / \mathrm{mL})$ than with $\mathrm{HD}(0.32 \pm$ $0.16 \mathrm{U} / \mathrm{mL}$ ). It was concluded that there were differences in plasma oxidants/antioxidants between Boerboel dogs with normal hips and those with hip dysplasia suggesting their role in the pathogenesis of canine hip dysplasia

Key words: antioxidants, Boerboel, prevalence, hip dysplasia, malondialdehyde, trace elements

\section{INTRODUCTION}

Canine hip dysplasia is a heritable, polygenic, developmental disease of the coxofemoral joint of rapidly growing larger breeds such as Rottweiler, Labrador Retrievers, German shepherd dogs and
Boerboel dogs having both environmental and genetic components (Janutta \& Distl, 2006; Coopman et al., 2008). It is characterised by remodelling of the head of the femur and/or acetabulum with resultant 
luxation and osteoarthritic changes (Sanchez-Molano et al., 2014). Secondary osteoarthritis results in pain and lameness. Genetic and environmental factors play key roles in canine hip dysplasia. Environmental factors that contribute to canine hip dysplasia include the level of exercise and diet (Smith et al., 2006; Kirkby \& Lewis, 2012). High dietary concentrations of calcium and vitamin $\mathrm{D}$ have also been implicated in the pathogenesis of canine hip dysplasia (Sanchez-Molano et al., 2014).

Lipid peroxidation mediated by free radicals is considered to be the major mechanism of cell membrane destruction and cell damage. Free radicals are formed in both physiological and pathological conditions in mammalian tissues (Maneesh et al., 2005). The failure of the body's control of lipid peroxidation will result in the subsequent formation of lipid peroxides and free radicals, and the accumulation of their final products as malondialdehyde in different body tissues (Weigel et al., 2013). Canine articular chondrocytes actively produce reactive oxygen species (ROS). Age-related decline in the activity and number of mitochondria plays a critical role in protecting cells from ROS damage. The consequence of increased oxidative stress is deoxyribonucleic acid (DNA) damage and telomere shortening, leading to reduced matrix production, chondrocyte senescence and apoptosis (Davies et al., 2008). Increase ROS also upregulates pro-inflammatory cytokines and matrix metalloproteinase (MMP) factors that mediate cartilage degradation (Nakagawa et al., 2010). Thus, oxidative stress is a relevant part of OA and promotes cartilage destruction and inflammatory transformation (Ziskoven et al., 2010). However, there is no record of the role of oxidative stress in hip dysplasia.
Multiple defense systems against free radical-induced oxidative stress, collectively called antioxidants are present in the serum, plasma and erythrocytes (ElBarbary, 2011). Most of the antioxidant ability of serum is attributed to the presence of ascorbate, transferrin and ceruloplasmin. Erythrocytes are equipped to handle intracellular oxidative stress through the combined activities of catalase, superoxide dismutases, glutathione S-transferase, glutathione peroxidase and glutathione (McCord \& Edeas, 2005; Valko et al., 2007). The changes in plasma concentration of antioxidants during osteoarthritis have been well documented in humans and in experimental canine model of osteoarthritis (Goranov, 2007). However, there are no records of changes in plasma concentration of oxidant/antioxidants during hip dysplasia in dogs.

Many trace elements have been recognised to play important role in the pathogenesis and progression of many diseases, including osteoarthritis. Naturally occurring minerals such as magnesium, copper, manganese, selenium and zinc have shown anti-inflammatory effects in both animal and human studies (Wang et al., 2004). Inspite of the involvement of trace elements in the pathogenesis of a number of musculoskeletal diseases, their role in the pathogenesis of hip dysplasia is yet unknown. Recent report showed that there is an association between serum concentrations of trace elements and developmental hip dysplasia in humans (Guner et al., 2018). The present study therefore compares the plasma concentrations of product of lipid peroxidation, antioxidants and trace elements between Boerboels with or without hip dysplasia. 


\section{MATERIALS AND METHODS}

\section{Animals}

Twenty apparently healthy adult Boerboel dogs of both sexes with mean weight $54 \pm$ $7.54 \mathrm{~kg}$ and age ranging between $1-5$ years (median age: 2 years) were used. All dogs used were micro-chip identified and registered with Boerboel Dog Breeders Association of Nigeria (BDBAN) or Boerboel Alliance. Before the commencement of the study, informed owners consent and ethical approval from the College of Veterinary Medicine Research and Ethics Committee, Federal University of Agriculture, Abeokuta were obtained.

\section{Experimental design}

The study was a cross-sectional survey. All dogs used were presented for radiographic elbow and hip screening as part of appraisal criteria for registration under the Kennel Union of South Africa (KUSA). The dogs were divided into two groups based on their radiographic hip classification using the Fédération Cynologique Internationale (FCI) criteria. Dogs with hip classifications $\mathrm{A} 1, \mathrm{~A} 2, \mathrm{~B} 1$ and $\mathrm{B} 1$ were classified as non-dysplastic or normal, while dogs with hip classifications C1, C2, D1, D2, E1 and E2 were classified as dysplastic.

\section{Radiographic examination}

The dogs were premedicated with intramuscular injections of $0.5 \mathrm{mg} / \mathrm{kg}$ of $2 \%$ xylazine hydrochloride (Xylazine $20 \mathrm{Inj}^{\circledR}$, Kepro, Holland) and $0.04 \mathrm{mg} / \mathrm{kg}$ atropine sulphate (Atocan ${ }^{\circledR}$, Sishui Xierkang Pharma, China). Thereafter, anaesthesia was induced with $4 \mathrm{mg} / \mathrm{kg}$ of $1 \%$ propofol injection (Diprivan, ICI - Zeneca Pharmaceuticals) intravenously. Extended anteroposterior and flexed lateral radiographs were obtained in all the dogs. All the ra- diographs were obtained with a digital Xray machine using a Potter-Bucky grid. Exposure parameters ranged from 10-16 $\mathrm{mAs}$ and $74-80 \mathrm{kVp}$ depending on the size of the dog.

\section{Blood collection and analyses}

Prior to anaesthesia, about $5 \mathrm{~mL}$ of blood was collected from the cephalic vein of each dog into bottle containing EDTA for the determination of plasma concentrations of malondialdehyde (MDA), superoxide dismutase, glutathione, glutathione peroxidase, Vitamin E, manganese ( $\mathrm{Mn})$, copper $(\mathrm{Cu})$, cobalt $(\mathrm{CO})$ and magnesium $(\mathrm{Mg})$. Following blood collection, the samples were centrifuged at $2555 \times g$ and the plasma was aspirated into Eppendorf tubes and kept frozen until assay.

Malondialdehyde analysis. Plasma concentration of MDA was determined according to the method of Buege \& Aust (1978): $0.05 \mathrm{~mL}$ of plasma was added to $1.0 \mathrm{~mL}$ of thiobarbituric acid (TBA) reagent and then incubated in boiling water bath for $15 \mathrm{~min}$. The tube was placed immediately under a running tap to cool down and was centrifuged at $2555 \times \mathrm{g}$ for $10 \mathrm{~min}$. The absorbance of the clear supernatant was read against blank at 535 $\mathrm{nm}$. The concentration of TBARS (MDA) was calculated as Concentration (M) = Absorbance/ $\varepsilon$, where $\varepsilon$ is the extinction coefficient of MDA-TBA complex at $535 \mathrm{~nm}\left(1.56 \times 10^{5} \mathrm{M}^{-1} \mathrm{~cm}^{-1}\right)$.

Superoxide dismutase (SOD). SOD was determined according to the method of Marklund \& Marklund (1974). Two test tubes were marked as blank (B) and test $(\mathrm{T}) ; 100 \mu \mathrm{L}$ of potassium phosphate buffer, $830 \mu \mathrm{L}$ of distilled water $\left(\mathrm{dH}_{2} \mathrm{O}\right)$ were pipetted into tube $\mathrm{B}$. The tubes were incubated for $10 \mathrm{~min}$ at $25{ }^{\circ} \mathrm{C}$ and $20 \mu \mathrm{L}$ of pyrogallol was added to both tubes. They were then mixed by inversion and 
the absorbance was recorded on a spectrophotometer for $3 \mathrm{~min}$ at $420 \mathrm{~nm}$. The difference between the initial and final absorbance and average absorbance difference were calculated $(\Delta 420 / \mathrm{min})$. SOD activity was calculated as: $\%$ Inhibition $=$ $[(\Delta \mathrm{A} 420 \mathrm{~nm} / \mathrm{min}$ Blank- $\Delta \mathrm{A} 420 \mathrm{~nm} / \mathrm{min}$ of sample $) /(\Delta \mathrm{A} 420 \mathrm{~nm} / \mathrm{min}$ Blank $] \times 100$

Glutathione $(G S H)$. GSH concentration was determined according to the method of Ellman (1959). To this end, 0.5 $\mathrm{mL}$ of plasma $(5 \mu \mathrm{L}$ of plasma $+495 \mu \mathrm{L}$ of $\mathrm{dH}_{2} \mathrm{O}$ ) was added to $0.5 \mathrm{~mL}$ of $10 \%$ trichloroacetic acid and the mixture was centrifuged for $15 \mathrm{~min}$ at $2555 \times \mathrm{g}$. Then $0.4 \mathrm{~mL}$ of the supernatant was added to $0.8 \mathrm{~mL}$ of $0.4 \mathrm{M}$ Tris buffer $\mathrm{pH} 8.9$ and 20 $\mu \mathrm{L}$ of freshly prepared 5,5'-dithiobis-(2nitrobenzoic acid) (DTNB). Absorbance was read within 5 min of DTNB addition on a spectrophotometer at $412 \mathrm{~nm}$ against blank containing water instead of plasma. The concentration of GSH was calculated as: $\mathrm{mM} \mathrm{GSH}=$ Absorbance $\times 2.44 \times$ 14.15 , where $14.15 \mathrm{Mm}^{-1} \mathrm{~cm}^{-1}$ is the molar extinction coefficient of DNTB and 2.44 is the dilution factor of sample in $1.22 \mathrm{~mL}$ assay mixture

Glutathione peroxidase (GPX). GPX was determined according to the method of Rotruck et al. (1973). Two test tubes were marked blank (B) and test (T), 200 $\mu \mathrm{L}$ of $0.4 \mathrm{M}$ potassium phosphate buffer $\mathrm{pH} 7.0,100 \mu \mathrm{L}$ of sodium azide, $200 \mu \mathrm{L}$ of $10 \mathrm{mM}$ glutathione, $100 \mu \mathrm{L}$ of $0.2 \mathrm{mM}$ hydrogen peroxide and $200 \mu \mathrm{L}$ of plasma was pipetted into tube $\mathrm{T}$ while $400 \mu \mathrm{L}$ of $0.4 \mathrm{M}$ potassium phosphate buffer $\mathrm{pH} 7.0$, $100 \mu \mathrm{L}$ of sodium azide, $200 \mu \mathrm{L}$ of 10 $\mathrm{mM}$ glutathione and $100 \mu \mathrm{L}$ of $0.2 \mathrm{mM}$ hydrogen peroxide was pipetted into tube B. They were incubated at $37{ }^{\circ} \mathrm{C}$ for 10 min, 10\% trichloroacetic acid (TCA) was added to both tubes and the mixtures was centrifuged for $15 \mathrm{~min}$ at $2555 \times \mathrm{g}$. Then
$400 \mu \mathrm{L}$ of the supernatant was added to $800 \mu \mathrm{L}$ of $0.4 \mathrm{M}$ Tris buffer $\mathrm{pH} 8.9$ and 20 $\mu \mathrm{L}$ of freshly prepared DTNB. Absorbance was read within 5 min after adding DTNB at $412 \mathrm{~nm}$ against reagent blank. The activity of glutathione peroxidase was calculated in terms of concentration of glutathione utilised as $\mathrm{mM} \mathrm{GSH}=\mathrm{Ab}$ sorbance / 14.15 , where 14.15 is the molar extinction coefficient of DNTB.

Glutathione peroxidase activity was calculated as: $\{\Delta \mathrm{OD} / \mathrm{min} \times \mathrm{GSH}$ Std. $\times$ total reaction volume $\} \div\{$ Std. $\mathrm{OD} \times 307.32 \times$ volume of enzyme source $\times \mathrm{Hb}$, where 307.32 is the molecular weight of GSH.

Copper. Plasma concentration of copper was determined by a colorimetric method using copper colorimetric assay kit (Abnova, Taiwan) as described below: Three tubes were labelled as Sample Test (ST), Sample Blank (SB) and Reagent Blank (RB). Then $100 \mu \mathrm{L}$ of distilled water was transferred into RB; $20 \mu \mathrm{L}$ of 1.5 $\mathrm{mg} / \mathrm{dL}$ standard and $80 \mu \mathrm{L}$ distilled water (final $300 \mu \mathrm{g} / \mathrm{dL} \mathrm{Cu} 2+$ ) was added into $\mathrm{SB} ; 100 \mu \mathrm{L}$ of plasma was transferred into ST. To each tube, $35 \mu \mathrm{L}$ Reagent A (trichloroacetic acid) was added and vortexed. One hundred $\mu \mathrm{L}$ of ST, SB and RB was pipetted into separate wells of a clear flat-bottom 96-well plate, $150 \mu \mathrm{L}$ of working reagent was added to each well and mixed thoroughly. The mixture was incubated for $5 \mathrm{~min}$ at room temperature and optical density read at $359 \mathrm{~nm}$. The corrected absorbance of the sample (ST$\{\mathrm{SB}+\mathrm{RB}\})$ was used to determine amount of copper by using extinction coefficient derived from the calibration curve.

Manganese. Plasma concentration of manganese was determined by colorimetric method using Manganese Assay Kit (Sigma Aldrich CO, UK): $10 \mu \mathrm{L}$ of plasma was pipetted into duplicate wells 
in the plate. $10 \mu \mathrm{L}$ of assay buffer was then be added into duplicate wells as Zero calibrator, $50 \mu \mathrm{L}$ of the substrate preparation was added to each well using a repeater pipet. Twenty-five $\mu \mathrm{L}$ xanthine oxidase preparation was added to each well using a repeater pipette. The sample was incubated at room temperature for 20 min. The optical density was read at 450 nm.

Magnesium. Plasma Mg concentration was measured colorimetrically. Magnesium in plasma reacts with calmagite in alkaline medium forming a coloured complex. Three tubes were labelled as sample test (ST), sample blank (SB) and reagent blank (RB). Twenty $\mu \mathrm{L}$ of the plasma was added to each ST and SB and $20 \mu \mathrm{L}$ of TRIS solution to RB. Eighty $\mu \mathrm{L}$ of calmagite 80 was added to each tube, vortexed and incubated at room temperature for $10 \mathrm{~min}$. Sixty $\mu \mathrm{L}$ of EGTA was added into each tube except SB, into which 200 $\mu \mathrm{L}$ of dietylamine was added. Absorbance was read at $480 \mathrm{~nm}$ after $5 \mathrm{~min}$. The corrected absorbance of the sample (ST$\{\mathrm{SB}+\mathrm{RB}\})$ was used to determine amount of magnesium by using extinction coefficient derived from the calibration curve

Cobalt. Plasma concentration of copper was determined by colorimetric method using cobalt colorimetric assay kit (Sigma Aldrich CO, UK). Three tubes were labelled as Sample Test (ST), Sample Blank (SB) and Reagent Blank (RB). One hundred $\mu \mathrm{L}$ of plasma was added to each ST and SB and $100 \mu \mathrm{L}$ of TRIS solution to RB. Ten $\mathrm{mL}$ of the cobalt reagent was added to each reaction (well), mixed well using a horizontal shaker and incubated the reaction for $10 \mathrm{~min}$ at room temperature. The absorbance is then measured at $475 \mathrm{~nm}$. The corrected absorbance of the sample $(\mathrm{ST}-\{\mathrm{SB}+\mathrm{RB}\})$ was used to determine amount of cobalt by using extinction coefficient derived from the calibration curve.

Vitamin E. Plasma concentration of Vitamin E was determined spectrophotometrically using the method described by Rutkowski et al. (2005) - $0.5 \mathrm{~mL}$ anhydrous ethanol was added to $0.5 \mathrm{~mL}$ plasma in a test-tube with a tight stopper and shaken vigorously for $1 \mathrm{~min}$. Then $0.25 \mathrm{~mL}$ of xylene was added and shaken vigorously for another minute. The tube was centrifuged to separate the extract $(1500 \times g, 10 \mathrm{~min})$, and $0.25 \mathrm{~mL}$ batophenanthroline solution added to $1.5 \mathrm{~mL}$ of the extract (upper layer). $\mathrm{FeCl}_{3}$ solution $(0.25 \mathrm{~mL})$ was then added to the mixture and mixed vigorously. Finally, $0.25 \mathrm{~mL}$ $\mathrm{H}_{3} \mathrm{PO}_{4}$ solution was added to the mixture. The absorbance of the test sample and of the standard sample was then measured at $539 \mathrm{~nm}$ against the blank test. Plasma concentration of Vitamin $\mathrm{E}$ was calculated as Vitamin $\mathrm{E}=\mathrm{a} / \mathrm{A}$, where $\mathrm{a}=$ difference in absorbance of test samples and standard sample, and $\mathrm{A}=$ absorbance of blank.

\section{Statistical analysis}

Data were presented as mean and standard deviation. Appropriateness of sample size was determined by $\mathrm{N}$-power analysis. Correlation between the parameters was done using Pearson's correlation coefficient. Differences in plasma concentrations of trace elements, MDA and antioxidants between male and female Boerboels and between Boerboels with normal hips and those with hip dysplasia were determined using un-paired student t-test. Differences were considered significant at $\mathrm{P} \leq 0.05$. All statistical analyses were performed using Statistical Package for the Social Sciences (SPSS) 17.0 software (SPSS Inc., Chicago, IL, USA). 


\section{RESULTS}

The hip scores of the Boerboel dogs in shown in Table 1. Four (4) of the dogs had hip grade of A1 or A2 (on both left and right hip, while five (5) and seven (7) dogs had hip scores of B1 or B2 on left and right hip respectively. In addition, six (6) and three (3) dogs had scores of $\mathrm{C} 1$ or $\mathrm{C} 2$ on left and right hip respectively, while four (4) and five (5) dogs had hip scores of D1 or D2 on the left and right hip respectively. Only one dog had a hip score of E1 or E2 in either left or right hip. The sex distribution of the hip grades in apparently normal Boerboel dogs in this study is shown in Table 2. Five (5/9) of the male Boerboel dogs were dysplastic, vs six (6/11) dysplastic females.

Table 1. Radiographic hip scores in apparently healthy Boerboel dogs

\begin{tabular}{ccc}
\hline \multirow{2}{*}{$\begin{array}{c}\text { Patient iden- } \\
\text { tification }\end{array}$} & \multicolumn{2}{c}{ Radiographic hip scores } \\
\cline { 2 - 3 } & Sex & Left/Right Hip \\
\hline 1 & $\mathrm{~F}$ & $\mathrm{D}_{1} / \mathrm{D}_{2}$ \\
2 & $\mathrm{~F}$ & $\mathrm{~A}_{1} / \mathrm{A}_{1}$ \\
3 & $\mathrm{~F}$ & $\mathrm{C}_{1} / \mathrm{C}_{2}$ \\
4 & $\mathrm{M}$ & $\mathrm{D}_{1} / \mathrm{D}_{2}$ \\
5 & $\mathrm{M}$ & $\mathrm{D}_{2} / \mathrm{D}_{2}$ \\
6 & $\mathrm{~F}$ & $\mathrm{D}_{1} / \mathrm{D}_{2}$ \\
7 & $\mathrm{~F}$ & $\mathrm{E}_{1} / \mathrm{E}_{2}$ \\
8 & $\mathrm{~F}$ & $\mathrm{~A}_{2} / \mathrm{A}_{2}$ \\
9 & $\mathrm{~F}$ & $\mathrm{C}_{1} / \mathrm{C}_{2}$ \\
10 & $\mathrm{M}$ & $\mathrm{A}_{1} / \mathrm{A}_{1}$ \\
11 & $\mathrm{M}$ & $\mathrm{C}_{2} / \mathrm{B}_{1}$ \\
12 & $\mathrm{M}$ & $\mathrm{B}_{1} / \mathrm{B}_{2}$ \\
13 & $\mathrm{M}$ & $\mathrm{A}_{2} / \mathrm{A}_{2}$ \\
14 & $\mathrm{~F}$ & $\mathrm{~B}_{1} / \mathrm{B}_{2}$ \\
15 & $\mathrm{~F}$ & $\mathrm{~B}_{2} / \mathrm{B}_{1}$ \\
16 & $\mathrm{M}$ & $\mathrm{C}_{2} / \mathrm{C}_{1}$ \\
17 & $\mathrm{~F}$ & $\mathrm{~B}_{1} / \mathrm{B}_{1}$ \\
18 & $\mathrm{~F}$ & $\mathrm{C}_{2} / \mathrm{D}_{1}$ \\
19 & $\mathrm{M}$ & $\mathrm{B}_{2} / \mathrm{B}_{1}$ \\
20 & $\mathrm{M}$ & $\mathrm{C}_{1} / \mathrm{B}_{2}$ \\
\hline
\end{tabular}

Table 2. Sex distribution of hip dysplasia in apparently healthy Boerboel dogs

\begin{tabular}{lccc}
\hline & \multicolumn{3}{c}{ Hip quality } \\
\cline { 2 - 4 } & Normal & Dysplastic & $\begin{array}{l}\text { Percentage } \\
\text { dysplastic }\end{array}$ \\
\hline Male & 4 & 5 & $25 \%$ \\
Female & 5 & 6 & $30 \%$ \\
\hline Total & 9 & 11 & $55 \%$ \\
\hline
\end{tabular}

There were no significant differences in the plasma concentration of the trace elements between Boerboel dogs with normal hip and those with hip dysplasia (Table 3). However, the plasma manganese and copper tended to be higher in Boerboel dogs with normal hips than those with hip dysplasia, while that of magnesium tended to be higher in dogs with hip dysplasia.

Plasma concentrations of MDA was significantly lower $(\mathrm{P}<0.05)$ in Boerboel dogs with normal hip than those with hip dysplasia, while the plasma concentrations of SOD was significantly $(\mathrm{P}<0.05)$ higher in Boerboel dogs with normal hips than those with hip dysplasia (Table 4). In addition, the plasma concentrations of GSH, GPX and vitamin E tended to be higher in Boerboel dogs with normal hip than those with hip dysplasia. However the differences were not significantly different.

Plasma Mn concentrations were negatively correlated to plasma copper and cobalt, while plasma cobalt was negatively correlated to copper (Table 5). There were no significant $(\mathrm{P}>0.05)$ correlations between the plasma concentrations of the trace elements. Similarly, there were no significant $(\mathrm{P}>0.05)$ correlations between MDA and the antioxidants (Table 6). Plasma concentrations of Vitamin E were negatively correlated to GPX. 
Table 3. Mean plasma concentrations of trace elements in normal and dysplastic Boerboel dogs

\begin{tabular}{lllc}
\hline Trace elements & Dysplastic dogs $(\mathrm{n}=9)$ & Normal dogs $(\mathrm{n}=11)$ & P value \\
\hline Manganese $(\mu \mathrm{mol} / \mathrm{L})$ & $8.01 \pm 3.3$ & $9.10 \pm 2.9$ & 0.549 \\
Copper $(\mu \mathrm{mol} / \mathrm{L})$ & $0.94 \pm 1.57$ & $1.57 \pm 2.04$ & 0.555 \\
Cobalt $(\mu \mathrm{mol} / \mathrm{L})$ & $0.008 \pm 0.004$ & $0.008 \pm 0.003$ & 0.581 \\
Magnesium $(\mu \mathrm{mol} / \mathrm{L})$ & $0.67 \pm 0.08$ & $0.64 \pm 0.14$ & 0.976 \\
\hline
\end{tabular}

Table 4. Mean plasma concentrations of malondialdehyde (MDA), superoxide dismutase (SOD), glutathione (GSH) and glutathione peroxidase (GPX) in normal and dysplastic Boerboel dogs.

\begin{tabular}{lccc}
\hline Parameters & Dysplastic dogs $(\mathrm{n}=9)$ & Normal dogs $(\mathrm{n}=11)$ & P value \\
\hline MDA $(\mu \mathrm{mol} / \mathrm{L})$ & $0.75 \pm 0.84$ & $1.77 \pm 0.78$ & 0.027 \\
SOD $(\mathrm{U} / \mathrm{mL})$ & $0.65 \pm 0.22$ & $0.32 \pm 0.16$ & 0.051 \\
GSH $(\mu \mathrm{mol} / \mathrm{L})$ & $0.06 \pm 0.02$ & $0.05 \pm 0.01$ & 0.765 \\
GPX $(\mathrm{U} / \mathrm{L})$ & $37.03 \pm 15.76$ & $32.06 \pm 2.93$ & 0.584 \\
Vitamin E $(\mu \mathrm{mol} / \mathrm{L})$ & $19.89 \pm 3.92$ & $18.13 \pm 6.43$ & 0.048 \\
\hline
\end{tabular}

Table 5. Pearson correlation coefficients (r) and levels of significance (P) among plasma concentrations of trace element in Boerboel dogs with hip dysplasia $(n=11)$

\begin{tabular}{lllll}
\hline & $\mathrm{Mn}$ & $\mathrm{Cu}$ & $\mathrm{Co}$ & $\mathrm{Mg}$ \\
\hline \multirow{2}{*}{$\mathrm{Mn}$} & & $\mathrm{r}=-0.044$ & $\mathrm{r}=-0.030$ & $\mathrm{r}=0.077$ \\
& & $\mathrm{P}=0.186$ & $\mathrm{P}=0.231$ & $\mathrm{P}=0.179$ \\
$\mathrm{~N} \mathrm{Cu}$ & $\mathrm{r}=-0.044$ & & $\mathrm{r}=0.036$ & $\mathrm{r}=0.325$ \\
& $\mathrm{P}=0.186$ & & $\mathrm{P}=0.440$ & $\mathrm{P}=0.670$ \\
\hline \multirow{2}{*}{$\mathrm{Co}$} & $\mathrm{r}=0.030$ & $\mathrm{r}=0.036$ & & $\mathrm{r}=0.287$ \\
& $\mathrm{P}=0.231$ & $\mathrm{P}=0.440$ & & $\mathrm{P}=0.581$ \\
\hline \multirow{2}{*}{$\mathrm{Mg}$} & $\mathrm{r}=0.077$ & $\mathrm{r}=-0.325$ & $\mathrm{r}=0.287$ & \\
& $\mathrm{P}=0.179$ & $\mathrm{P}=0.670$ & $\mathrm{P}=0.581$ & \\
\hline
\end{tabular}

\section{DISCUSSION}

The results of this study showed that the plasma concentration of MDA was significantly lower in Boerboel dogs with normal hip than those with hip dysplasia, while the plasma concentrations of SOD was significantly higher in Boerboel dogs with normal hip than those with hip dysplasia. In addition, the plasma concentrations of other antioxidants and trace elements tended to be higher in Boerboels with normal hips.
In this study, the incidence of hip dysplasia did not differ between the female and male Boerboel dogs. It has been reported that the odd ratio for hip dysplasia is higher in the female than male dogs (Loder \& Todhunter, 2017). However, in another prevalence study of hip dysplasia in Rottweilers and Labrador retrievers, there were no significant difference in the prevalence of hip dysplasia between the male and the female (Kirberger, 2017). It appears as though sex did not significantly 
influence the risk for the development of hip dysplasia in the Boerboel dogs.

The role of oral antioxidant in the management of canine hip dysplasia has been reported (Impellizeri et al., 1998), although the evidence was considered to be insufficient (Kirkby \& Lewis, 2012). Decrease in the expression of SOD has been associated with the early stage of osteoarthritis and linked to an increase in concentration of reactive oxygen species (Scott et al., 2010). In this study, plasma concentration of SOD was significantly lower in Boerboel dogs with hip dysplasia than dogs with normal hips. This finding is similar to that reported in humans with osteoarthritis (Angthong et al., 2013) and further supports the role of ROS in the pathogenesis of canine hip dysplasia and the possible usefulness of antioxidant supplementation in the management of hip dysplasia.

High dietary concentrations of calcium and vitamin D have been implicated in the pathogenesis of canine hip dysplasia (Sanchez-Molano et al., 2014). There are no report of the role of trace elements such as copper, cobalt, manganese and magnesium in the pathogenesis of canine hip dysplasia despite the reported role of these elements in musculoskeletal functions (Wang et al., 2004; King et al., 2005; Strecker et al., 2013). The results of this study showed that there were no significant differences in the plasma concentration of these trace elements between Boerboel dogs with normal hip and those with hip dysplasia, even though the plasma concentrations of copper and manganese tended to be higher in Boerboel dogs with normal hip than those with hip dysplasia. This result despite not being significant may suggest the possible role of these trace elements in the pathogenesis of hip dysplasia.

A recent report showed that there is an association between serum concentrations of trace elements and developmental hip dysplasia in humans (Guner et al., 2018). In the study, it was hypothesised that the association may actually be between trace element concentrations and synthesis of collagen (Guner et al., 2018). In this study, there was no significant difference in blood trace elements between dogs with normal hip and those with hip dysplasia. This result seems to be contrary to earlier findings in humans and may be associated with some of the limitations to this present study.

Table 6. Pearson correlation coefficients (r) and levels of significance (P) among plasma oxidants/antioxidants in Boerboel dogs with hip dysplasia $(n=11)$

\begin{tabular}{llllll}
\hline & MDA & SOD & GSH & GPX & Vit. E \\
\hline \multirow{2}{*}{ MDA } & & $\mathrm{r}=-0.276$ & $\mathrm{r}=0.242$ & $\mathrm{r}=0.223$ & $\mathrm{r}=0.110$ \\
& & $\mathrm{P}=0.597$ & $\mathrm{P}=0.992$ & $\mathrm{P}=0.494$ & $\mathrm{P}=0.318$ \\
\hline \multirow{2}{*}{ SOD } & $\mathrm{r}=-0.276$ & & $\mathrm{r}=0.045$ & $\mathrm{r}=0.352$ & $\mathrm{r}=0.232$ \\
& $\mathrm{P}=0.597$ & & $\mathrm{P}=0.478$ & $\mathrm{P}=0.494$ & $\mathrm{P}=0.187$ \\
\hline \multirow{2}{*}{ GSH } & $\mathrm{r}=0.242$ & $\mathrm{r}=0.045$ & & $\mathrm{r}=0.006$ & $\mathrm{r}=0.116$ \\
& $\mathrm{P}=0.992$ & $\mathrm{P}=0.478$ & & $\mathrm{P}=0.992$ & $\mathrm{P}=0.826$ \\
\hline \multirow{2}{*}{ GPX } & $\mathrm{r}=0.223$ & $\mathrm{r}=0.352$ & $\mathrm{r}=0.006$ & & $\mathrm{r}=-0.320$ \\
& $\mathrm{P}=0.494$ & $\mathrm{P}=0.494$ & $\mathrm{P}=0.992$ & & $\mathrm{P}=0.597$ \\
\multirow{2}{*}{ Vit E } & $\mathrm{r}=0.110$ & $\mathrm{r}=0.232$ & $\mathrm{r}=0.116$ & $\mathrm{r}=-0.320$ & \\
& $\mathrm{P}=0.318$ & $\mathrm{P}=0.187$ & $\mathrm{P}=0.826$ & $\mathrm{P}=0.597$ & \\
\hline
\end{tabular}


Finally, there were few limitations in this study. The number of dogs sampled might be considered to be small, although the $\mathrm{N}$ power analysis performed showed that the sample size was sufficient. Another probable limitation is the fact the dogs are from different breeders with possibly different feeding and exercise schedules. These might have influenced the plasma levels of the antioxidants and trace elements in the dogs. In addition, the different age of the dogs may mean that they are at different progression of hip dysplasia, although most of the dogs were up to 2 years of age.

In conclusion, the plasma concentrations of trace elements were higher in Boerboel dogs with normal hips than in those with hip dysplasia, although the differences were not significant. Therefore, we were not able to establish an association between trace elements and hip dysplasia in Boerboel dogs. In addition, the plasma concentrations of MDA and antioxidants changes significantly between Boerboel dogs with normal hip and those with hip dysplasia. This study suggests the role of reactive oxygen species in the pathogenesis of developmental hip dysplasia in dogs.

\section{ACKNOWLEDGEMENTS}

The authors are grateful to the African Small and Companion Animal Network (AFSCAN) for the grant provided for this work.

\section{REFERENCES}

Angthong, C., N. P. Morales, W. Sutipornpalangkul, A. Khadsongkram, P. Pinsornsak \& B. Pongcharoen, 2013. Can levels of antioxidants in synovial fluid predict the severity of primary knee osteoarthritis: A preliminary study? Springer Plus 2, 652.
Buege, J. A. \& S. D. Aust, 1978. Microsomal lipid peroxidation. Methods in Enzymology, 52, 302-310.

Coopman, F., G. Verhoven, J. Saunders, L. Duchateau \& H. van Bree, 2008. Prevalence of hip dysplasia, elbow dysplasia and humeral head osteochondrosis in dog breeds in Belgium. The Veterinary Record, 163, 654-658.

Davies, G. M., F. Guilak, J. B. Weinberg \& B. Fermor, 2008. Reactive nitrogen and oxygen species in interleukins-1-mediated, DNA damage associated with osteoarthritis. Osteoarthritis \& Cartilage, 16, 624-630.

El-Barbary, A. M., M. A. Abdel-Khalek, A. M. Elsalawy \& S. M. Hazaa, 2011. Assessment of lipid peroxidation and antioxidant status in rheumatoid arthritis and osteoarthritis patients. The Egyptian Rheumatologist, 33, 179-185.

Ellman, G. L., 1959. Tissue sulfhydryl groups. Archives of Biochemistry and Biophysics, 82, 70-77.

Goranov, N. V., 2007. Serum markers of lipid peroxidation, antioxidant enzymatic defense, and collagen degradation in an experimental (Pond-Nuki) canine model of osteoarthritis. Veterinary Clinical Pathology, 36, 192-195.

Guner, S., S. I. Guner, M. A. Gokalp, M. F. Ceylan, S. Unsal \& S. H. Demir, 2018. Do the trace elements play a role in the aetiopathogenesis of developmental dysplasia of hip? European Review for Medical and Pharmacological Sciences 22, 910-913.

Impellizeri, J. A., R. E. Lau \& F. Azzara,1998. Fourteen week clinical evaluation of an oral antioxidant as a treatment for osteoarthritis secondary to canine hip dysplasia. Veterinary Quarterly, 20, S107-S108.

Janutta, V. \& O. Distl, 2006. Inheritance of canine hip dysplasia: Review of estimation methods and of database. Heritability estimates and prospects on further developments. Deutsche Tierrztliche Wochenschrift, 113, 6-12. 
King, D. E., A. G. Mainous, M. E. Geesey, \& R. F. Woolson, 2005. Dietary magnesium and C-reactive protein levels. Journal of American College of Nutrition 24, 166-171.

Kirberger, R. M., 2017. Phenotypic hip and elbow dysplasia trends in Rottweilers and Labrador retrievers in South Africa (20072015): Are we making progress. Journal of South African Veterinary Association, 88, e1-e10. doi: 10.4102/jsava.v88i0.1534.

Kirkby, K. A. \& D. D. Lewis, 2012. Canine hip dysplasia: Reviewing the evidence for nonsurgical management. Veterinary Surgery 41, 2-9.

Loder, R. T. \& R. J. Todhunter, 2017. Demographics of canine hip dysplasia in the United States and Canada. Journal of Veterinary Medicine, https://doi.org/10.1155/ $2017 / 5723476$.

Maneesh, M., H. Jayalekshmi, S. Dutta, A. Chakrabarti \& D. M. Vasudevan, 2005. Effect of chronic ethanol administration on testicular antioxidant system and steroidogenic enzyme activity in rats. Indian Journal of Environmental Biology, 43, 445449.

Marklund, S. \& G. Marklund, 1974. Involvement of superoxide anion radical in the antioxidation of pyrogative and convenient assay for superoxide dismutase. European Journal of Biochemistry, 47, 469-474.

McCord, J. M. \& M. A. Edeas, 2005. SOD, oxidative stress and human pathologies: A brief history and a future vision. Biomedicine \& Pharmacotherapy, 59, 139-142.

Nakagawa, S., Y. Arai \& O. Madza, 2010. Nacetylsteine prevents nitric oxide-induced chondrocyte apoptosis and cartilage degeneration in an experimental model of osteoarthritis. Journal of Orthopaedic Research, 28, 156-163.

Rotruck, J. T., A. L. Pope, H. E. Ganther, A. B. Swanson, D. G. Hafeman, \& W.G. Hoekstra, 1973. Selenium: Biochemical role as a component of glutathione peroxidase. Science, 179, 588-590.

Rutkowski, M., K. Grzegorczyk \& M. T. Paradowski, 2005. Colorimetric method of blood plasma total vitamin $\mathrm{E}$ determination. Diagnostic Laboratory, 41, 375-380.

Sánchez-Molano, E., J. A. Woolliams, R. Pong-Wong, D. N. Clements, S. C. Blott \& P.Wiener, 2014. Quantitative trait loci mapping for canine hip dysplasia and its related traits in UK Labrador Retrievers. BMC Genomics, 15, 833.

Scott, J. L., R. K. Gabrielides, R. K. Davidson, T. E. Swingler, L. M. Clark, G. A. Wallis, R. P. Boot-Handford, T. B. Kirkwood, R. W. Taylor \& D. A. Young, 2010. Superoxide dismutase down-regulation in osteoarthritis progression and end-stage disease. Annals of Rheumatic Diseases, 69, $1502-1510$

Smith, G. K., E. R. Paster, M. Y. Powers, D. F. Lawler, D. N. Biery, F. S. Shofer, P. J. McKelvie \& R. D. Kealy, 2006. Lifelong diet restriction and radiographic evidence of osteoarthritis of the hip joint in dogs. Journal of American Veterinary Medical Association, 229, 690-693.

Strecker, D., A. Mierzecki \& K. Radomska, 2013. Copper levels in patients with rheumatoid arthritis. Annals of Agricultural and Environmental Medicine, 20, 312-316.

Valko, M., D. Leibfritz, J. Moncol, M. T. D., Cronin, M. Mazur \& J. Telser, 2007. Free radicals and antioxidants in normal physiology functions and human disease. International Journal of Biochemistry \& Cell Biology, 39, 44-84.

Wang, A. G., T. Xia, R. Ru, J. Yuan, X. M. Chen \& K. D. Yang, 2004. Antagonistic effect of selenium on oxidative stress, DNA damage, and apoptosis induced by fluoride in human hepatocytes. Fluoride, 37, 107-110.

Weigel, R. A., A. S. Lima, A. A. Morgado, G. R. Nunes, M. M. Miriam, S. F. Hagen, W. R. Fernandez \& M. C. Sucupira, 2013. Oxidative metabolism and muscle biochemical profile of polo horses supplemented with an ADE vitamin complex. Pesquisa Veterinaria Brasileira, 33, 58-62.

Ziskoven, C., M. Lager, C. Zilkens, W. Bloch, K. Brixus, \& R. Krauspe. 2010. Oxidative 
R. A. Ajadi, J. L. Sanni, E. F. Sobayo \& O. K. Ijaopo

stress in secondary osteoarthritis: From cartilage destruction to clinical presentation? Orthopaedic Reviews (Praha), 2, 23.

Paper received 13.06.2018; accepted for publication 02.10 .2018

\section{Correspondence:}

Dr. R. A. Ajadi

Department of Veterinary Medicine

and Surgery,

Federal University of Agriculture, Abeokuta PMB 2240, Alabata Road, Abeokuta,

Ogun State, Nigeria

tel: 234-703-380-0326

e-mail: ade_vsr@hotmail.com 